\title{
Recycled Flexible Resins in Concrete
}

\author{
Abdel-Azim A. Abdel-Azim ${ }^{\dagger}$ and Aiman M. Atta
}

Egyptian Petroleum Research Institute, 1 Ahmed El-Zomor street, 7th region, Nasr City, Cairo, Egypt

(Received April 30, 1996)

\begin{abstract}
Depolymerization of poly(ethylene terephthalate) (PET) waste was performed in presence of manganese acetate catalyst. Different ratios of diethylene glycol (DG) to propylene glycol (PG) was used for glycolysis. The weight ratio of PET to the glycols mixture was $1: 0.65$. The hydroxyl value of the glycolyzed products were determined and the amount of free glycol in each case was analyzed. These glycolyzed products were reacted with maleic anhydride (MA) to prepare a series of unsaturated polyesters having different molecular weights. These polyesters were dissolved in styrene monomer and their curing behavior was investigated. The DG was used to impart flexibility to the cured resin. The compressive strength of the polymer concretes (PC) made with these resins were measured and was found to be comparable to PC made from virgin materials.
\end{abstract}

KEY WORDS Unsaturated Polyester / Polymer Concrete / Propylene Glycol / Diethylene Glycol / Poly(ethylene terephthalate) / Styrene / Curing / Glycolysis / Recycling /

Polymer concrete (PC) formed from a resin and inorganic fillers are very strong and durable material and has a variety of applications. ${ }^{1}$ The excellent mechanical and durability properties of the material reduce maintenance and repair activities. The very fast cure time of the material impart an important advantage for this type of concrete in mending bridges and floors in industrial facilities. PC is an excellent material for precast components because the fast cure time enables the fast and efficient use of forms and other production facilities. ${ }^{2}$ In addition to adequate strength and bond, resins for bridge deck overlays require high elongation and low modulus to provide compatibility with thermal movements. Flexible resins should be used to accomplish this requirement.

Work done recently has shown that the production of unsaturated polyester resins based on recycled poly(ethylene terephthalate) (PET), is possible. ${ }^{3}$ The PET wastes are typically found in scrap textile and beverage bottles that are collected after use in many locations and recycled in applications not requiring contact with food. If resins made with recycled PET can be used to produce good-quality $\mathrm{PC}$ at a potentially lower cost, their use will be important to the success of the PC industry. The recycling of PET in PC will also help lessen an environmental problem. ${ }^{3}$ This article deals with recycling of PET for the sake of preparing flexible resins and evaluates the feasibility of using the recycling products in producing durable PC.

\section{EXPERIMENTAL}

\section{Synthesis of Unsaturated Polyester (UP) Resins}

The PET textile waste (EI-Mehala El-Kobra Co.) was depolymerized using ten different mixtures of diethylene glycol (DG) and propylene glycol (PG) in presence of manganese acetate as a trans-esterification catalyst. The concentration of the catalyst was $0.5 \%$ (by weight) based on the weight of the PET. The weight of the glycol mixture used for glycolysis was $65 \%$ of the weight of PET. The

\footnotetext{
$\dagger^{\dagger}$ To whom all correspondence should be addressed.
}

reaction was carried out at temperature about $200^{\circ} \mathrm{C}$ under reflux for $4 \mathrm{~h}$ in nitrogen atmosphere, and at $210-230^{\circ} \mathrm{C}$ for $3 \mathrm{~h}$. The temperature of the reaction system was then allowed to drop to $100^{\circ} \mathrm{C}$ and maintained at this temperature for $1 \mathrm{~h}$. The temperature of the reaction mixture was allowed to drop to room temperature. The glycolyzed products were then analyzed for hydroxyl value and the amount of free glycols. The hydroxyl values were determined by the conventional acetic anhydride/pyridine method. ${ }^{4}$ In order to determine the amount of the free glycol, a weighed quantity of the glycolyzed product was extracted with water and filtered. The aqueous filtrate containing free glycol and some water-soluble oligomers was concentrated by evaporation of water. The water-soluble oligomers were separated by precipitation from the free glycol by cooling the filtrate. The precipitated water-soluble oligomers were filtered and added to the residue remaining after the first filtration and weighed together. The difference between the initial and the final weights represents the amount of free glycol removed by water extraction.

The UP resins were prepared by reacting the glycolyzed products with maleic anhydride at a value of the hydroxyl to carboxyl ratio of 1.1/1. The hydroxyl number of the glycolyzed product before removing the free glycol was used to determine the amount of maleic anhydride. The reactions were carried out in an esterification reactor. The reactants were heated from room temperature to $180^{\circ} \mathrm{C}$ in nitrogen atmosphere in about $1.5 \mathrm{~h}$. Then the temperature was held at $180^{\circ} \mathrm{C}$ for $4 \mathrm{~h}$ and finally raised to $200^{\circ} \mathrm{C}$ and maintained until the acid value reached about $30 \mathrm{mg} \mathrm{KOH} \mathrm{g}^{-1}$. The acid value was monitored throughout the course of the reaction. The acid value was determined by titrating the solution of the weighed quantity of resin in acetone, with about $0.2 \mathrm{~N}$ standard alcoholic $\mathrm{KOH}$ solution using phenolphthalein indicator. The water of the reaction was removed throughout the course of the reaction. At the end of the reaction the temperature of the entire contents of the reactor was allowed to drop to $100^{\circ} \mathrm{C}$, then diluted with styrene containing hydroquinone as an inhibitor. 


\section{Determination of Peak Exotherm}

The curing exotherms of unsaturated polyesters were measured with a Digitron digital differential thermometer, type $\mathrm{K}$, model 3202 with a resolution of $0.1^{\circ} \mathrm{C}$, as described in the previous work. ${ }^{6,7}$ The formulation used for curing was resin-initiator-accelerator $=100: 2$ : 0.2 (parts by weight). ${ }^{8}$

\section{Preparation of Polymer Concrete $(P C)$}

There are no standard tests that are directly applicable to PC specimens. However, in the evaluation of mechanical properties of PC and polymer mortar (PM) materials, ASTM standard applicable to cement-based materials was used as guideline.

Different types of unsaturated polyester resins were used for preparing the cylindrical specimens. The PC mix design was optimized for workability, strength, and economy. The aggregate composition was 50\% $10-\mathrm{mm}$ pea gravel, 35\% sand, and 15\% fly ash (fly ash makes the mix both more workable and stronger). The aggregate-to-resin ratio was 9:1. Methyl ethyl keton peroxide (MEKP) initiator and cobalt octoate (CO) activator were added to the resin immediately prior mixing. Mixing of the aggregate with the activated resin was done for a period of about three minutes. Specimens were then cast in a steel mold under mild pressure to maintain the desired height of the cylinder. The specimens were allowed to cure at room temperature. The age at testing was 10 days to assure complete curing.

\section{Mechanical Properties}

The compressive stress-strain diagrams were measured using a Zwick mechanical testing machine as described in the previous work. ${ }^{9}$ A constant loading rate of $44500 \mathrm{Nmin}^{-1}$ was applied. The specimens were cylinders of $25-\mathrm{mm}$ diameter and $50-\mathrm{mm}$ height.

\section{RESULTS AND DISCUSSION}

\section{Preparation and Characterization of the Glycolyzed Prod- ucts}

Ten glycolyzed products, coded $\mathrm{G}-1-\mathrm{G}-10$, were obtained by reacting PET with PG/DG mixtures having $0.8,0.75,0.7,0.65,0.60,0.55,0.50,0.45,0.40$, and 0.35 weight fractions of $\mathrm{PG}$. The ratio of glycol mixture to PET waste was kept constant $(0.65)$ in all depolymerization reactions of PET with different glycol mixtures. The DG was utilized among the glycol systems to impart flexibility to the final cured resin. Tong et al. ${ }^{10}$ found the unsaturated polyester based on bis(2-hydroxyethyl)terephthalate, maleic anhydride and ethylene glycol was not compatible with styrene monomer. These authors found that it is necessary to substitute part of ethylene glycol with propylene glycol to enhance the compatibility of the product with the styrene monomer. Accordingly, in the present study, the PG was combined with DG to increase the miscibility of the synthesized resins with styrene monomer. We presumed that the incorporation of the hydroxypropylene in the glycolyzed products increases the lipophylicity of the polymers based on these glycolyzed products and consequently, enhances their solubility in styrene monomer.

The free glycol in each of these glycolyzed products
Table I. Characterization of glycolized PET waste ${ }^{\mathrm{a}}$

\begin{tabular}{ccccc}
\hline Oligomer & $\begin{array}{c}\text { Weight } \\
\text { fraction of } \\
\text { PG }\end{array}$ & $\begin{array}{c}\text { Free } \\
\text { glycol/\% }\end{array}$ & $\begin{array}{c}\text { OH value } \\
(1)\end{array}$ & $\begin{array}{c}- \text { OH value } \\
(2)\end{array}$ \\
\hline G- 1 & 0.80 & 61.0 & 974 & 348 \\
G- 2 & 0.75 & 61.2 & 952 & 340 \\
G- 3 & 0.70 & 61.5 & 924 & 336 \\
G- 4 & 0.65 & 61.8 & 913 & 332 \\
G- 5 & 0.60 & 62.1 & 885 & 322 \\
G- 6 & 0.55 & 62.3 & 850 & 309 \\
G- 7 & 0.50 & 62.3 & 804 & 295 \\
G- 8 & 0.45 & 62.4 & 750 & 276 \\
G- 9 & 0.40 & 62.5 & 694 & 250 \\
G-10 & 0.35 & 62.7 & 635 & 233 \\
\hline
\end{tabular}

a $-\mathrm{OH}$ value $(1)=$ hydroxyl value before free glycol removal; $-\mathrm{OH}$ value (2) = Hydroxyl value after free glycol removal; Amount of glycol mixture $=65 \%$ of the weight of PET waste.

was measured according to the procedure described in the experimental section. The resultant data for the glycolyzed products are tabulated in Table I in conjunction with the hydroxyl number before and after removing the free glycol. The measured values of free glycols indicate that only about $2-4 \%$ of the glycols are used up in the transesterification. This finding runs in harmony with that found in our previous publication. ${ }^{11}$ With respect to the hydroxyl numbers after removing the free glycol, it is obvious that there is a gradual decrease from $348 \mathrm{mg} \mathrm{KOH} \mathrm{g}^{-1}$ to $233 \mathrm{mg} \mathrm{KOH} \mathrm{g}^{-1}$, with decreasing the weight fraction of $\mathrm{PG}$ in the glycol mixture from 0.80 to 0.35 . This reduction in the hydroxyl number reveals that the extent of depolymerization decreases with decreasing amount of PG in the glycol mixture. The hydroxyl numbers after removing the free glycols indicate that the extent of depolymerization is considerable and the glycolyzed products mainly terminated with hydroxyl groups. Based on the obtained values of the hydroxyl number after removing the free glycol and the ${ }^{1} \mathrm{H}$ NMR study carried out by Tong et al., ${ }^{10}$ the following monomer, dimer, and trimer compounds are exist:

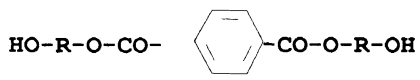

$$
\begin{aligned}
& \text { OH-R-O-CO- } \mathrm{C}_{6} \mathrm{H}_{4}-\mathrm{CO}-\mathrm{O}-\left(\mathrm{CH}_{2}\right)_{2} \mathrm{O}-\mathrm{CO}-\mathrm{C}_{6} \mathrm{H}_{4}-\mathrm{CO}-\mathrm{O}-\mathrm{R}-\mathrm{OH} \\
& \text { OH-R-O-(CO- } \left.\mathrm{C}_{6} \mathrm{H}_{4}-\mathrm{CO}-\mathrm{O}-\mathrm{CH}_{2} \mathrm{CH}_{2}-\mathrm{O}\right)_{2}-\mathrm{CO}-\mathrm{C}_{6} \mathrm{H}_{4}-\mathrm{CO}-\mathrm{O}-\mathrm{R}-\mathrm{OH}
\end{aligned}
$$

In these formulae $\mathrm{R}$ may be:

$$
\mathrm{CH}_{2} \mathrm{CH}_{2}, \mathrm{HC}\left(\mathrm{CH}_{3}\right) \mathrm{CH}_{2} \text { or }\left(\mathrm{CH}_{2} \mathrm{CH}_{2} \mathrm{O}\right)_{2}
$$

\section{Synthesis of UP Resins}

The oligomers G-1-G-10 were reacted with MA to produce the UP resins, coded UP-80-UP-35, respectively. The hydroxyl number of the glycolyzed product before separation of the free glycol was used for estimating the amount of MA. The results of the characterization of the prepared unsaturated polyester resins are given in Table II. In this table the measured values of acid and hydroxyl numbers are listed in columns 3 and 4 , respectively. These values were used for determining the number average molecular weight for each of the synthesized unsaturated polyester. ${ }^{4}$ In all cases, 
Table II. Characterization of the UP resins obtained from the PET waste

\begin{tabular}{|c|c|c|c|c|}
\hline \multirow[t]{2}{*}{ Polyester } & \multirow{2}{*}{$\begin{array}{c}\text { Glycolized } \\
\text { product } \\
\text { used }\end{array}$} & $\begin{array}{c}\text { Carboxyl } \\
\text { value }\end{array}$ & $\begin{array}{l}\text { Hydroxyl } \\
\text { value }\end{array}$ & $\begin{array}{c}\text { Molecular } \\
\text { weight }\end{array}$ \\
\hline & & $\mathrm{mg} \mathrm{KOH} \mathrm{g}^{-1}$ & $\mathrm{mg} \mathrm{KOH} \mathrm{g}^{-1}$ & $M_{n}$ \\
\hline UP - 80 & G- 1 & 30 & 63 & 1206 \\
\hline UP-75 & G- 2 & 30 & 62 & 1219 \\
\hline UP-70 & G- 3 & 32 & 60 & 1219 \\
\hline UP-65 & G- 4 & 28 & 63 & 1232 \\
\hline UP-60 & G- 5 & 32 & 59 & 1233 \\
\hline UP-55 & G- 6 & 33 & 57 & 1246 \\
\hline UP-50 & G- 7 & 30 & 60 & 1247 \\
\hline UP-45 & G- 8 & 30 & 60 & 1247 \\
\hline UP-40 & G- 9 & 31 & 58 & 1260 \\
\hline UP-35 & G-10 & 30 & 57 & 1290 \\
\hline
\end{tabular}

unsaturated polyesters of number average molecular weight ranging between 1206 and 1290 were obtained. This range of molecular weights is comparable to that obtained by Vaidya and Nadkarni ${ }^{5}$ who prepared three polyesters having molecular weights ranging between 1045 and 1325. At first glance, the data quoted in Table II show that the molecular weight increases with increasing the DG content in the glycolyzed products. This may attributed to the increase in the average molecular weight of the glycolized product that reacted with maleic anhydride in order to synthesize the unsaturated polyester resin.

The curing exotherms of the prepared formulae were obtained by plotting the curing temperature as a function of time. Since the amount of heat evolved upon curing depends on the sample size, it was desirable to consider this parameter. For this reason it was very important to use glass bottles of the same volume in all measurements to achieve the repeatability of the measurements and affording legitimate comparative study. Some of these plots, for brevity, are illustrated in Figure 1. The maximum curing temperatures, $T_{\max }$, and the times, $t_{\max }$, required to reach these temperatures were obtained from these plots and tabulated in Table III.

In our previous publication, ${ }^{9}$ a series of UP resins based on phthalic anhydride, maleic anhydride and different glycol mixtures was prepared. The structure of formula No. 5 in this series is almost similar to the structure of UP resins prepared in the present study. The UP chains in the former formula contain $o$-phthalate group instead of the ethylene terephthalate group existing in the present formulae. The characteristics of formula 5 are shown in last raw in Table III. Comparing the curing characteristics of these two types of formulae reveals that the existence of terephthalate group increases the curing reaction time by about $30-50 \%$ and reduces the heat evolved during cure by about $4-10 \%$. This may be attributed to the increase of the distance between the curable double bonds. This increase of the distance is afforded by the extra $-\mathrm{CH}_{2}-\mathrm{CH}_{2}-$ moiety existing in the recycled formulae as well as the position of the two ester groups in terephthalate moiety. It can be seen also that $T_{\max }$ decreases with decreasing the content of PG and hence an increase in $t_{\max }$ is obtained. This finding afford a great body of evidence that the structure of the UP chains affecting the amount of heat liberated while curing Polym. J., Vol. 29, No. 1, 1997

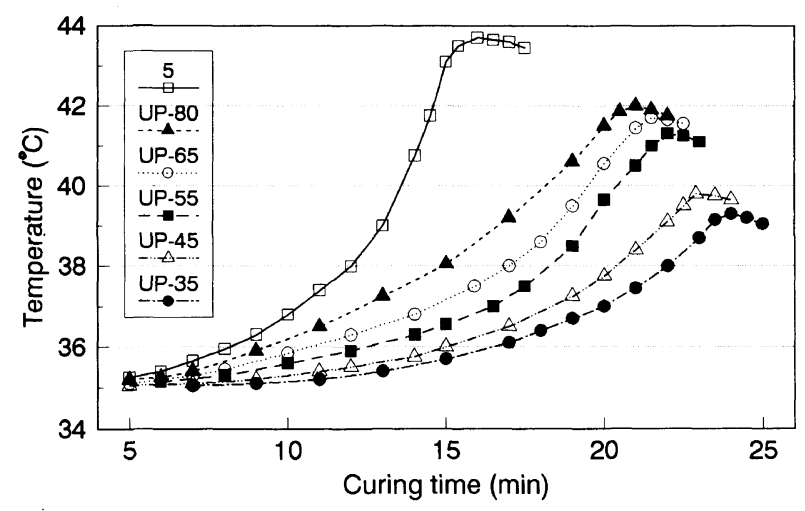

Figure 1. Curing exotherms for some selected recycled UP formulae.

Table III. Curing behavior of UP resins and mechanical properties of PC specimens based on these resins ${ }^{a}$

\begin{tabular}{|c|c|c|c|c|c|}
\hline \multirow{2}{*}{ Polyester } & \multirow{2}{*}{$\begin{array}{l}\text { Glycolized } \\
\text { product } \\
\text { used }\end{array}$} & \multirow{2}{*}{$\frac{t_{\max }}{\min }$} & \multirow{2}{*}{$\frac{T_{\max }}{{ }^{\circ} \mathrm{C}}$} & \multicolumn{2}{|c|}{ Mechanical properties } \\
\hline & & & & $\sigma_{\mathrm{u}}(\mathrm{MPa})$ & $E(\mathrm{GPa})$ \\
\hline UP-80 & G- 1 & 21.0 & 42.0 & 112.5 & 20.5 \\
\hline UP-75 & G- 2 & 21.3 & 41.8 & 110.3 & 19.0 \\
\hline UP-70 & G- 3 & 21.4 & 41.7 & 107.5 & 17.5 \\
\hline UP-65 & G- 4 & 21.5 & 41.7 & 105.6 & 16.0 \\
\hline UP-60 & G- 5 & 21.7 & 41.5 & 104.3 & 15.2 \\
\hline UP-55 & G- 6 & 22.0 & 41.3 & 104.0 & 14.8 \\
\hline UP-50 & G- 7 & 22.5 & 41.1 & 100.0 & 12.9 \\
\hline UP-45 & G- 8 & 22.9 & 39.8 & 97.1 & 11.7 \\
\hline UP-40 & G- 9 & 23.5 & 39.6 & 95.9 & 9.9 \\
\hline UP-35 & G-10 & 23.9 & 39.3 & 92.2 & 7.8 \\
\hline+5 & - & 16.0 & 43.7 & - & - \\
\hline
\end{tabular}

a + Data for formula No. 5 published in ref 9 .

as well as the curing time.

\section{Preparation and Characterization of $P C$}

The PC samples were prepared from the UP resins obtained from recycling of PET in conjunction with a constant aggregate composition. The aggregate composition, molding technique and the equipment used for casting the PC specimens were described in detail in the experimental section.

The measured values of compressive strength $\left(\sigma_{u}\right)$ and Young's modulus $(E)$, according to ASTM method (D 695 44T), of the PC based on the recycled resins are shown in Table III. This table shows that $\sigma_{\mathrm{u}}$ decreases from $112.5 \mathrm{MPa}$ to $92.2 \mathrm{MPa}$ upon increasing the weight fraction of DG from 0.2 to 0.65 while the corresponding values of $E$ decreases from $20.5 \mathrm{GPa}$ to $7.8 \mathrm{GPa}$. The range of the measured values of $\sigma_{\mathrm{u}}$ for PCs is slightly higher than the value obtained by Rebeiz et al. $(91.8 \mathrm{MPa})^{12}$ for a PC based on a commercial recycled UP from PET. On the other hand the same authors reported $^{2}$ values of $\sigma_{\mathrm{u}}$ ranging between $42.1 \mathrm{MPa}$ and 87.3 MPa for six different PCs based on different commercial patterns of recycled UP resins. The difference between the present values of $\sigma_{\mathrm{u}}$ and that reported by Rebeiz et $a .^{2,12}$ may be attributed to the difference in molecular weights of the resins. Industrial preparation of UP resins in large batches certainly leads to a wider molecular weight distribution compared to UP resins prepared in a laboratory scale. A further reason which 
may influences the $\sigma_{U}$ of the cured specimen is the procedure used for shaping this specimen. It is well known that the presence of voids is responsible for introducing weak points in the moulded specimens. In their work, Rebeiz et al..$^{2,12}$ have used an ordinary casting procedure. In the present work, the casting was performed under a tender pressure. This pressure certainly leads to a very low void content. This reduction in the void content enhances the mechanical properties. For the same PC specimens, Rebeiz et al. ${ }^{2}$ reported values of Young's modulus ranging between $10.3 \mathrm{GPa}$ and $28.4 \mathrm{GPa}$. The lower values of $E$ (higher flexibility) obtained in the present investigation seem due to the incorporation of DG molecules in the UP chains. This enhanced flexibility may be attributed to the increase of the length of the repeating units in the UP chains which results in a better local freedom of motion of these chains and hence increases the flexibility.

PCs made from virgin materials ${ }^{2}$ were found to have compressive strengths ranging from 40 to $130 \mathrm{MPa}$. Thus, the properties of PCs made with resins using recycled PET are comparable to those using virgin resins.

\section{CONCLUSIONS}

The following conclusions may be drawn from the above mentioned results:

(1) the PET waste could be depolymerized by glycolysis with PG-DG mixtures,

(2) the extent of depolymerization increases with increasing amount of $\mathrm{PG}$,

(3) the existence of terephthalate group increases the curing reaction time and reduces the heat evolved during cure,

(4) the structure of the UP chains affecting the amount of heat liberated while curing as well as the curing time

(5) the UP resins designed from recycled PET may be used for making PC,

(6) embodiment of $\mathrm{DG}$ in the glycolyzed product increases the flexibility of the cured PC.

\section{REFERENCES}

1. K. S. Rebeiz, D. W. Fowler, and D. R. Paul, Proceedings of the Third International Symposium "Mechanics of Polymer Composites," Institute of Theoretical and Applied Mechanics, Prague, 16th-18th April, 1991 p 367.

2. K. S. Rebeiz, D. W. Fowler, and D. R. Paul, Plastics Engineering, February, 33 (1991)

3. K. S. Rebeiz and D. W. Fowler, Polym.-Plast. Tech. Eng., 30 (8), 809 (1991).

4. W. R. Sorenson and T. W. Campbell, "Preparative Method of Polymer Chemistry," Interscience, New York, N.Y., 1968, p 155.

5. U. R. Vaidya and V. M. Nadkarni, J. Appl. Polym. Sci., 34, 235 (1987).

6. A. A. Abdel-Azim, I. A. Attia, and E. S. Nasr, Polym.-Plast. Technol. Eng., 34 (1), 79 (1995).

7. A. A. Abdel-Azim, B. H. Mahmoud, and M. S. Farhat, Polym. Adv. Technol., 5, 269 (1994).

8. E. S. Nasr and A. A. Abdel-Azim, Polym. Adv. Technol., 3, 407 (1992).

9. A. A. Abdel-Azim, E. S. Nasr, and M. S. Farhat, Polym. J., 26 (4), 423 (1993).

10. S. N. Tong, D. S. Chen, C. C. Chen, and L. Z. Chung, Polymer, 24, 469 (1993).

11. A. A. Abdel-Azim and I. A. Attia, Polym. Advanc. Technol., 6, 688 (1995).

12. K. S. Rebeiz, D. W. Fowler, and D. R. Paul, J. Appl. Polym. Sci., 44, 1649 (1992). 